\title{
Quality of Life among Family Caregivers of Patients Undergoing Hemodialysis
}

\author{
DALIA I. ABD EL-AZEM, M.Sc.; NAWAL A. FOUAD, D.N.Sc. and EMAN M. SEIF EL-NASR, D.N.Sc. \\ The Department of Community Health Nursing, Faculty of Nursing, Cairo University
}

\begin{abstract}
Background: Family caregivers of patients undergoing hemodialysis have a lot of great responsibilities toward their patients additional to their daily own obligations which affect their health and quality of life.

Aim of Study: To assess the quality of life among family caregivers of patients undergoing hemodialysis.

Material and Methods: Design: A descriptive research design was utilized in this study.

Setting: Hemodialysis unit which belongs to outpatient clinics of El-Kasr El-Aini University Hospital.

Sample: A convenient sample of 130 family caregivers of patients undergoing hemodialysis were included in the study from March to August 2017.

Tool for Data Collection: Two tools were used to collect data pertinent to the study. First tool "structured family caregiver questionnaire" which consisted of two parts. First part: Questionnaire about demographic characteristics of the family caregivers. Second part: Questionnaire about demographic characteristics of the patients undergoing hemodialysis. Second tool (WHOQOL Tool): Consisted of 100 questions about quality of life among family caregivers of patients undergoing hemodialysis cover six main domains: Physical, social, psychological, level of dependence, environmental and spiritual domains.
\end{abstract}

Results: Study results revealed that the mean WHOQOL domain scores were 34.83 for the physical domain, 73.57 for the psychological domain, 49.40 for the level of dependence domain, 37.37 for the social relationships domain, 82.55 for the environmental domain and 16.93 for the spiritual domain; There was statistical significant positive correlation found between satisfaction with own health and mean scores of physical, psychological, environmental domains ( $p=0.007$, $.003, .005$ respectively) and there was statistical significant positive correlation found between own evaluation of QOL and mean scores of physical, psychological, social domains ( $p=0.010, .009, .005$ respectively), also there was a highly statistical significant positive correlation between own evaluation of QOL and mean scores of spiritual domain ( $p=.002)$.

Correspondence to: Dr. Dalia I. Abd El-Azem, The Department of Community Health Nursing, Faculty of Nursing, Cairo University
Conclusion: The study concluded that, the environmental and psychological domains showed the highest scores (82.55 and 73.57 , respectively), while the spiritual domain showed the lowest score 16.93 .

Recommendations: The study recommended that before the beginning of dialysis therapy, health professionals should identify and explore patient' needs and potential caregiver in the family of patient and established empowerment programs to prepare them for the task to be carried out, mainly in the initial phase of their activities.

Key Words: Family caregiver - Patients undergoing hemodialysis - Quality of life.

\section{Introduction}

QUALITY of Life (QOL) is a broad multidimensional concept that usually includes subjective evaluations of both positive and negative aspects of life. It is a broad ranging concept affected in a complex way by the person's health status including, physical, psychological health, level of dependence, social relationships and personal beliefs [1]. Today, with increased life expectancy, chronic diseases have been a major health problem. Chronic renal failure is considered as one of the main problems of general health, it's a devastating medical, social, and financial problem for patients and their family caregivers [2].

One of the chosen replacement therapies for chronic renal failure patients is Hemodialysis (HD), which is considered a highly invasive treatment and very costly chronic therapy, as it involves high economic, physical and psychosocial costs for the patient and their family caregivers. Additionally, HD generates many needs and complications in patients that most often cannot be satisfied by the patients themselves and cannot be resolved during their stay at the hemodialysis unit; therefore, they require direct and continuous home care [3]. Home care for HD patients is very important in the treatment process, but generates complications and 
challenges for the organization of family activities and family economics; the manner in which families cope with such complications affects patients and their family caregiver quality of life [4].

Caregiving presents considerable challenges; physical, emotional and economic for the family caregivers. As, providing long-term help to HD patients on an everyday basis in addition to the family caregivers' own obligations may be a serious physical and psychological burden on them. Also, the level of patients' dependency on the family caregivers increases with time due to the nature of the disease and HD complications. So, caregiving for HD patients has a profound and pervasive effect on the physical, social and emotional well-being of family caregivers and their quality of life [5]

Family caregivers perform physical, psychological, social, financial support and continuous care for patients; they help patients with many daily activities, including transportation the dialysis centers, symptoms management, mobility, dressing, and preparing an appropriate renal diet. Family caregivers have a lot of responsibilities inside and outside home in addition to their own daily obligations which can affect their health at varying degrees. Long term care for HD patients who dependent on them may result feeling of frustration, worry and guilt. Although family caregivers suffer a lot to care for their patients, they often receive a little attention and the main focus is always on the patient [6].

Family health nurse has an important role in educating the family caregivers about coping strategies to overcome daily obstacles, resolve stresses, empower them for better coping with daily challenges and manage their informational needs about the complex health system and patients' needs. Moreover, coordinates and collaborates between the family caregivers and government programs, advocacy groups and agencies. Furthermore, works as liaison between family caregivers and support groups to share different experiences which help improving their quality of life [7].

\section{Significance of the study:}

End Stage Renal Disease (ESRD) is the silent epidemic of the 21 st century and its occurrence is universal. It is not only a clinical concern, but also a growing economic and organizational problem. In Egypt, ESRD is growing annually, the estimated annual incidence of ESRD is around 74 per million and the total prevalence of patients on dialysis is 264 per million; also there are 90,000 patients who die each year because of kidney failure. Chronic kidney diseases are the seventh leading cause of death in Egypt [8].

There is an Egyptian study that was conducted in Tanta University, Egypt about the effect of family centered empowerment model on hemodialysis patients and their caregivers, the study included 50 hemodialysis patients and 50 caregivers. Result of the study revealed that all caregivers obtained severe burden level pre-empowerment due to caregiving for their patients while post empowerment $66 \%$ falls in mild to moderate level of burden. And the study recommended that before the beginning of dialysis therapy, health professionals should identify and explore patient needs and the need for family caregiver and establish empowerment programs to prepare them for the task [9].

As there is an increasing incidence and prevalence rate of patients treated by dialysis and because hemodialysis patients are vulnerable to complications before, during and after treatment, so hemodialysis patients need assistance in activities of daily living, longer caregiving duration by one or more family caregiver who suffer changing their life to adjust to caregiving process.

So, carrying out this research will help understanding the family caregivers' needs, problems, how the quality of life of family caregivers is affected by their caregiving process and determining the extent to which care results in burdens on caregivers. Also, these research findings could be beneficial in concluding recommendations which will help in improving the caregiving process and optimizing the quality of caregivers' life and maintaining their ability to support and care for patients. Furthermore, it is hoped that, this effort will generate attention and motivation for further researches in this area.

\section{Subjects and Methods}

\section{Research question:}

What is the quality of family caregivers' life of patients undergoing hemodialysis?

Sample: A convenient sample of 130 family caregivers of patients undergoing hemodialysis from El-Kasr El-Aini outpatient clinics waiting areas were included in the study from March to August 2017.

Setting: This study was conducted at Hemodialysis Unit which belongs to outpatient clinics of El-Kasr El-Aini University Hospital. This unit contains 65 beds in 10 rooms and 2 waiting areas for caregivers; one outside the unit and the other 
inside the unit. The Chronic Hemodialysis Unit provides a service of regular hemodialysis sessions weekly ( 6 days per week except Fridays) for the end stage renal disease patients who are not hospitalized. Patients are divided into two groups A \& $\mathrm{B}$, each group dialyzed three days/week.

Study design: Descriptive design was utilized to fulfill the aim of the study. As stated by Nandhini \& Rangarjan [10] the descriptive design finds out what is happening, generates new insights, asks questions, assesses phenomena in new light, generates ideas and seeks to give an accurate profile of people, events and situations.

Toolfor data collection: The data of this study was collected using the following two tools:

1- Structured family caregiver questionnaire: Which was developed by the investigator after extensive review of literature. It includes two parts:

Part I:Demographic characteristic of the family caregivers: It includes age, gender, educational level, marital status, income and relation to patient.-

Part II: Demographic characteristic of the patients: It includes age, gender, educational level, income and medical history of disease (onset of dialysis, presence of other chronic diseases).

2- WHO Quality of Life (WHOQOL) tool: Quality of life tool was adopted from the WHO team; 1995. It includes 100 questions covering six main domains: Physical, social, psychological, level of dependence, environmental and spiritual domains. Each domain includes several facets. Physical domain includes (3) Facets: Pain and discomfort, energy and fatigue, rest and sleep. Psychological domain includes (5) Facets: Bodily image and appearance, positive and negative feelings, thinking, learning, memory, concentration and self-esteem. Level of dependence includes (4) Facets: Mobility, dependence on medicinal substances and medical aids, activity of daily living and work capacity. Social domain includes (3) Facets: Personal relations, sexual activity and social support. Environmental domain includes (8) Facets: Safety, security, freedom, opportunities for acquiring new information and skills, physical environment, transportations, home environment, financial resources, opportunities for recreation/leisure, health and social care: Accessibility and quality. Spiritual domain includes (1) Facet: Religion/ spirituality/personal beliefs. There are four separate questions that examine general quality of life. The first question asks about an individual's overall perception of quality of life, the second question asks about an individual's satification with quality of life, the third question asks about an individual's general satification with life and the fourth question asks about an individual's overall perception of health.

\section{Validity and reliability:}

The initial reliability analyses showed a correlation coefficient of more than $0.4-0.8$. The validity of the tool ranged from R 0.244 and 0.676 (Abd El-Mouty, Abd El-Aziz \& Habib, 2004) [11].

Procedures: The official written permission was obtained from the Faculty of Nursing, Cairo University and the manager of the Kasr El-Aini then from the manager of Kasr El-Aini Unit of Dialysis, Nephrology and Transplantation. The investigator explained the aim and the nature of the research to family caregivers present in the unit with their patients according to the schedule of the unit. The investigator also emphasized family caregivers' right to accept or refuse participation in the research. A written informed consent was then obtained from every family caregiver who accepted to participate in the study. Individual interview was conducted by the investigator within 30 minutes in 2 waiting areas (one outside the unit and one inside the unit) with each family caregiver to complete structured family caregiver questionnaire and WHOQOL tool. The investigator collected data two days a week (one day for the group of family caregivers and hemodialysis patients who was attending Saturday, Monday and Wednesday weekly and another day for the group who was attending Sunday, Tuesday and Thursday weekly) around 3 to 4 family caregivers included from 8 am to $3 \mathrm{pm}$. Data collection process took 6 months (from March to August 2017).

Ethical considerations: Primary approval was obtained from the Research Ethics Committee at Faculty of Nursing-Cairo University. After that an official permission was taken from the hospital authorities of El-Kasr El-Eni University Hospital. The investigator informed the family caregivers about the purpose and nature of the study. The investigator emphasized that participation in this study is voluntary; each subject has the right to withdraw from the study when he/she wants. Anonymity and confidentiality was assured through coding of the data. Family caregivers were assured that this data will not be reused in another research without their permission, and the data collected will be used only for the research. Written consent was obtained from the family caregiver and oral consents then were obtained from the female students to participate in the study. 
Statistical analysis: Upon completion of data collection the data were scored, tabulated, analyzed by computer using the "Statistical Package for the Social Science"(SPSS) Version 20. Data were statistically described in terms of means, standard deviations, range, frequencies and percentages when appropriate. Relations between different numerical variables were tested using Pearson correlation. ANOVA test was used to test relations between demographic variables and knowledge and practice. $p$-values equal to or less than 0.05 was considered statistically significant and 0.001 or less was considered as highly statistically significant.

\section{Results}

Demographic characteristics of the study sample:

Table (1) $54.6 \%$ aged between 33 years or more with a mean age 34.02 and SD \pm 9.06 . While $60 \%$ were male and $40 \%$ were female. Regarding family caregivers" income, (Table 1) also depicts that, $67.7 \%$ didn't have enough income and need to borrow while only $1.5 \%$ had enough income and could save. As regard marital status, the highest percentage of the family caregivers were married $(60.8 \%)$ while only $7.7 \%$ were widow, only $6.1 \%$ could read and write while $30.8 \%$ were university educated. Regarding family caregivers' relation to patient $33.8 \%$ were spouse and $19.2 \%$ were mothers.

Table (1): Percentage distribution of the family caregivers of patients undergoing hemodialysis according to their demographic characteristics $(n=130)$.

\begin{tabular}{|c|c|c|}
\hline Variable & $\mathrm{N}$ & $\%$ \\
\hline $\begin{array}{l}\text { Age: } \\
\text { 18- } \\
\text { 25- } \\
\text { 33- } \\
\text { Mean } \pm \text { SD }\end{array}$ & $\begin{array}{c}30 \\
29 \\
71 \\
34.02 \pm 9.06\end{array}$ & $\begin{array}{l}23.1 \\
22.3 \\
54.6\end{array}$ \\
\hline $\begin{array}{l}\text { Gender: } \\
\text { Male } \\
\text { Female }\end{array}$ & $\begin{array}{l}78 \\
52\end{array}$ & $\begin{array}{l}60 \\
40\end{array}$ \\
\hline $\begin{array}{l}\text { Income: } \\
\text { Enough \& save } \\
\text { Enough } \\
\text { Not enough \& borrow }\end{array}$ & $\begin{array}{c}2 \\
40 \\
88\end{array}$ & $\begin{array}{l}1.5 \\
30.8 \\
67.7\end{array}$ \\
\hline $\begin{array}{l}\text { Marital status: } \\
\text { Single } \\
\text { Married } \\
\text { Divorced } \\
\text { Widow }\end{array}$ & $\begin{array}{c}34 \\
79 \\
7 \\
10\end{array}$ & $\begin{array}{l}26.2 \\
60.8 \\
5.4 \\
7.7\end{array}$ \\
\hline $\begin{array}{l}\text { Educational level: } \\
\text { Can't read and write } \\
\text { Read and write } \\
\text { Basic education } \\
\text { Secondary education } \\
\text { University education }\end{array}$ & $\begin{array}{c}28 \\
8 \\
20 \\
34 \\
40\end{array}$ & $\begin{array}{l}21.5 \\
6.1 \\
15.4 \\
26.2 \\
30.8\end{array}$ \\
\hline $\begin{array}{l}\text { Relation to patient: } \\
\text { Wife/husband } \\
\text { Sister/brother } \\
\text { Son/daughter } \\
\text { Other }\end{array}$ & $\begin{array}{l}44 \\
24 \\
37 \\
25\end{array}$ & $\begin{array}{l}33.8 \\
18.5 \\
28.5 \\
19.2\end{array}$ \\
\hline Total & 130 & $100 \%$ \\
\hline
\end{tabular}

\section{Quality of the family caregivers' life:}

Fig. (1) shows that mean WHOQOL domains scores were $34.83 \pm 6.47$ for the physical domain, $73.57 \pm 6.86$ for the psychological domain, $49.40 \pm$ 3.03 for level of dependence, $37.37 \pm 5.64$ for social relationships domain, $82.55 \pm 7.60$ for the environmental domain and $16.93 \pm 1.63$ for spiritual domain. The lowest mean score was for the spiritual domain while the highest mean score was for the environmental domain.

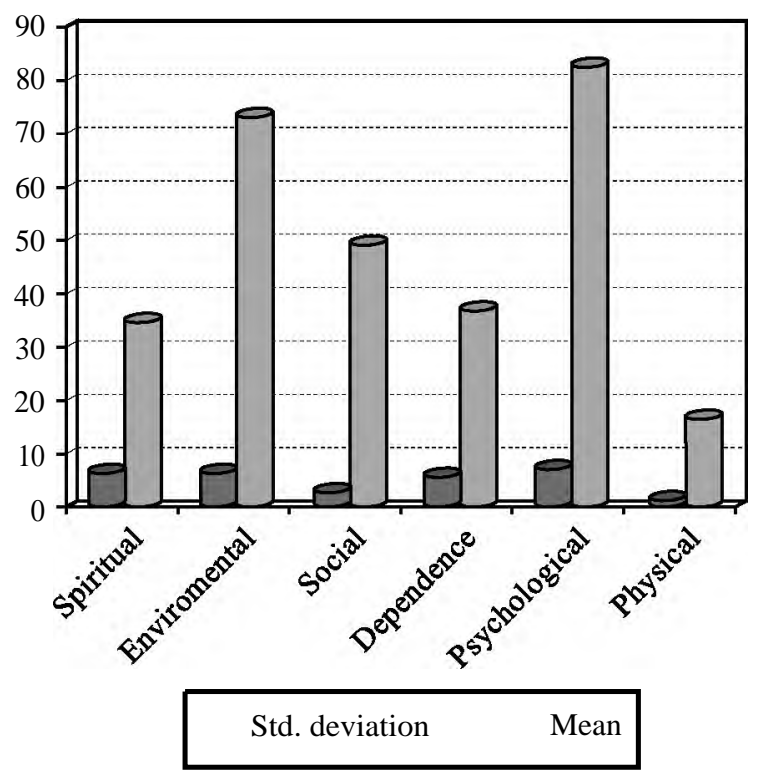

Fig. (1): Distribution of the family caregivers of patients undergoing hemodialysis according to mean scores of quality of life domains.

Relationship between quality of life for family caregivers and some demographic characteristics:

Table (2) shows that there was highly statistically significant relationship between income of family caregivers and mean scores of environmental quality of life domain $(p=0.000)$.

Table (2): Relationship between quality of life for family caregivers and their income level $(n=130)$.

\begin{tabular}{lcccccc}
\hline \multirow{2}{*}{ Variables } & \multicolumn{5}{c}{ Income } & \\
\cline { 2 - 5 } & $\begin{array}{c}\text { Enough } \\
\text { and save } \\
\mathrm{M} \pm \mathrm{SD}\end{array}$ & $\begin{array}{c}\text { Enough } \\
\mathrm{M} \pm \mathrm{SD}\end{array}$ & $\begin{array}{c}\text { Not enough } \\
\text { and barrow } \\
\mathrm{M} \pm \mathrm{SD}\end{array}$ & $\mathrm{F}$ & $p$ \\
\hline Physical & $33.00 \pm 1.41$ & $34.85 \pm 6.54$ & $34.87 \pm 6.54$ & .08 & .922 \\
Psychological & $64.50 \pm .70$ & $74.57 \pm 6.54$ & $73.32 \pm 6.94$ & 2.27 & .107 \\
Dependence & $46.00 \pm 1.41$ & $49.05 \pm 3.35$ & $73.57 \pm 6.86$ & 1.80 & .168 \\
Social & $31.00 \pm .001$ & $39.05 \pm 4.79$ & $36.76 \pm 5.85$ & 3.70 & .027 \\
Environmental & $93.00 \pm .001$ & $86.62 \pm 3.51$ & $30.73 \pm 5.88$ & 12.94 & $.000 * *$ \\
Spiritual & $16.00 \pm 141$ & $17.17 \pm 1.81$ & $16.85 \pm 1.55$ & .874 & .421 \\
\hline ***
\end{tabular}

**: Highly statistically significant. 
Table (3) shows that there was highly statistical significant relationship between relation to patient of family caregivers and mean scores of physical, psychological, social and environmental quality of life domain ( $p=0.005,0.000, .004,0.000$ respectively).

Table (3): Relationship between quality of life for family caregivers and their relation to patient $(\mathrm{n}=130)$.

\begin{tabular}{lcccccc}
\hline \multirow{2}{*}{ Variables } & \multicolumn{9}{c}{ Relation to patient } & & \\
\cline { 2 - 5 } & $\begin{array}{c}\text { Spouse } \\
\mathrm{M} \pm \mathrm{SD}\end{array}$ & $\begin{array}{c}\text { Sister or brother } \\
\mathrm{M} \pm \mathrm{SD}\end{array}$ & $\begin{array}{c}\text { Son or daughter } \\
\mathrm{M} \pm \mathrm{SD}\end{array}$ & $\begin{array}{c}\text { Mother } \\
\mathrm{M} \pm \mathrm{SD}\end{array}$ & $\mathrm{F}$ & $p$ \\
\hline Physical & $34.84 \pm 7.38$ & $37.20 \pm 4.08$ & $35.81 \pm 5.66$ & $31.12 \pm 6.45$ & 4.43 & $.005^{*}$ \\
Psychological & $74.45 \pm 6.47$ & $75.08 \pm 6.71$ & $75.56 \pm 5.53$ & $67.64 \pm 6.53$ & 9.43 & $.000^{* *}$ \\
Dependence & $48.79 \pm 2.66$ & $50.54 \pm 3.06$ & $49.48 \pm 2.96$ & $49.24 \pm 3.55$ & 1.77 & .155 \\
Social & $39.86 \pm 4.80$ & $36.16 \pm 6.22$ & $36.35 \pm 4.37$ & $35.68 \pm 6.81$ & 4.76 & $.004^{*}$ \\
Environmental & $83.97 \pm 6.92$ & $84.08 \pm 6.80$ & $83.67 \pm 6.49$ & $76.92 \pm 8.75$ & 6.38 & $.000^{* *}$ \\
Spiritual & $17.29 \pm 1.75$ & $16.04 \pm .75$ & $17.16 \pm 1.83$ & $16.84 \pm 1.43$ & 3.58 & .016 \\
\hline *. Statistically significant. & \multicolumn{2}{c}{$* *$ Highly statistically sionificant. } & &
\end{tabular}

Table (4) shows that there was a highly statistical significant positive correlation found between satisfaction with own health and mean scores of physical, psychological, environmental domains $(p=0.007, .003, .005$ respectively) and there was a highly statistical significant positive correlation found between own evaluation of QOL and mean scores of psychological, social and spiritual domains ( $p=.009, .005, .002$ respectively), also there was statistical significant positive correlation between own evaluation of QOL and mean scores of physical $(p=.010)$.

Table (4): Relationship between family caregivers of patients undergoing hemodialysis quality of life domains and general quality of life \& general health $(n=130)$.

\begin{tabular}{lcccccccc}
\hline $\begin{array}{l}\text { Family caregivers } \\
\text { quality of life } \\
\text { domains }\end{array}$ & \multicolumn{2}{c}{$\begin{array}{c}\text { Own evaluation } \\
\text { of QOL }\end{array}$} & \multicolumn{2}{c}{$\begin{array}{c}\text { Satisfaction with } \\
\text { own QOL }\end{array}$} & \multicolumn{2}{c}{$\begin{array}{c}\text { General satisfaction } \\
\text { with QOL }\end{array}$} & $\begin{array}{c}\text { Satisfaction with } \\
\text { own health }\end{array}$ \\
\cline { 2 - 9 } & $r$ & $p$ & $r$ & $p$ & $r$ & $p$ & $r$ & $p$ \\
\hline Physical & .224 & $.010^{*}$ & .060 & .433 & .15 & .073 & .23 & $.007^{*}$ \\
Psychological & .229 & $.009^{*}$ & .080 & .366 & .004 & .960 & .261 & $.003^{*}$ \\
Dependence & .138 & .118 & .095 & .284 & .029 & .745 & .145 & .100 \\
Social & .245 & $.005^{*}$ & .069 & .436 & .148 & .092 & .047 & .593 \\
Environmental & .059 & .504 & -.161 & .067 & -.217 & .013 & -.245 & $.005^{*}$ \\
Spiritual & .271 & $.002^{* *}$ & -.020 & .824 & .175 & .047 & .106 & .230 \\
\hline
\end{tabular}

*: Statistically significant.

**: Highly statistically significant.

\section{Discussion}

The result of the current study revealed that the highest percentage of the family caregivers aged between 34 years old and more with mean age $34.6 \pm 14.7$ years and the majority of the family caregivers were male This result was in agreement with the result of a study done by Gill et al., [10] in India who was assessed the quality of life of 68 family caregivers of patients suffering from chronic kidney disease found that the mean age of the family caregivers was $41.6 \pm 15.9$ years, the majority of them were male.

Regarding to income, the result of the current study showed that the majority of family caregivers had not enough income and needed to borrow. This result is consistent with Alnjadat, [11] who evaluated the socio-demographic characteristics of $137 \mathrm{Ma}-$ laysian caregivers of cancer patients in order to predict the factors affect their QOL and their care found that more than half of the caregivers rated their monthly income as unsatisfied.

The result of the current study revealed that the highest percentages of the family caregivers were married and more than third of the family caregivers were spouse. This result goes in the same line with the results of a study done by Pinedo et al., [12] on 119 primary caregivers to assess the QOL of patients after a stroke and their main caregivers found that more than half of caregivers were spouse.

The current study denoted that one third of the family caregivers were university graduated. This result is supported by a study done by Ogunlana, et al., [13] on 130 informal caregivers at University Teaching Hospital in Nigeria aimed to assess quality of life and burden of informal caregivers of stroke survivors found that half of caregivers were highly educated. 
This study revealed that, the lowest mean score was for the spiritual domain $16.93 \pm 1.63$ while the highest mean score was for the environmental domain $82.55 \pm 7.60$. This result was supported by Opoku-Boateng et al., [14] who assessed the economic cost and quality of life of 442 family caregivers of schizophrenic patients attending psychiatric hospitals in Ghana reported that the environmental domain for the family caregivers had the highest score and the lowest score was for the spiritual domain.

On the other hand, the results of a study done by Amendola, et al., [1 $\mathbf{r}$, aimed to assess the influence of social support on the quality of life of 100 family caregivers in Brazil while caring for people with dependence found that the physical and social relations domains showed the highest scores (66.7 and 60.9 , respectively), while the environmental domain showed the lowest scores (52.5). This difference in the results may be due to different cultures among the two studies which affect their QOL concept.

As regard income of the family caregivers, the present study illustrated that there was highly significant relationship between income of family caregivers and mean scores of environmental quality of life domain. This finding was supported by a study done by a study done by Winahyu, et al., [16] who assessed factors affecting quality of life among 137 family caregivers of patients with schizophrenia in a mental hospital in Jakarta, Indonesia found that the income of family caregivers was a significant factor affecting QOL while Vanz, et al., [17] evaluated the quality of life in 27 caregivers of children and adolescents with osteogenesis imperfecta in Spain found contracted results that there was not significant correlation between economic status of family caregivers and their QOL. This difference in the results may be due to most family caregivers in the study in Spain were unemployed mothers and the bread-winner of the family were the fathers. While, in the current study the highest percentage of the family caregivers were males, spouse and bread-winner of the family.

Concerning the relation to patient the current study revealed that there was statistical significant relationship between the family caregivers' relation to patient and mean scores of physical and social quality of life domain and there was highly statistically significant relationship between the family caregivers' relation to patient and mean scores of psychological and environmental quality of life domain. This result is supported by Kilic \& Kaptanogullari, [18] who evaluated the burden of 210 caregivers who provided care to hemodialysis patients in two different communities in Turkey reported that spouse caregivers had higher QOL when compared to the other relatives of the patients and the most affected QOL domain was the social domain. This result reflects that the family caregivers' relation to patient affects their QOL and the degree of that effect differs from case to another and according to different circumstances.

The current study revealed that there was statistical significant positive correlation found between satisfaction with own health and mean scores of physical, psychological, environmental domains and there was statistical significant positive correlation found between own evaluation of QOL and mean scores of physical, psychological, social domains, also there was a highly statistical significant positive correlation between own evaluation of QOL and mean scores of spiritual domain. Also, this result was supported by a study done by Yildirim, Kilic \& Akyol, [19] aimed to assess the relationship between life satisfaction and quality of life in 396 Turkish nursing school students found that there was a significant correlation between life satisfaction and the domains of quality of life scores and that there was a significant positive correlation between life satisfaction and quality of life domains.

Also, in the same line, a study was done by Garrido, et al., [20] to analyze the simultaneous relationship between life satisfaction and healthrelated quality of life found that there was positive correlation between satisfaction with own health and quality of life. This result reflects that satisfaction with health and satisfaction with QOL affect all QOL domains of life and that effect may differ according to different individuals circumstances.

\section{Conclusion:}

The study concluded that, the study concluded that, the environmental and psychological domains showed the highest scores (82.55 and 73.57, respectively), while the spiritual domain showed the lowest score 16.93 .

\section{Recommendations:}

Based on the current study results, the following recommendations can be made:

- Design educational programs to family caregivers regarding hemodialysis, its suspected complications and the needed care.

- Implementing an educational program to family caregivers regarding hemodialysis, its suspected complications and the needed care. 
- Design and implementing empowerment programs to family caregivers before starting hemodialysis sessions to prepare them for the task to be carried out.

\section{References}

1- MOLLAOGLU M. and DEVECI G.: Quality of Life in Patients with Chronic Renal Failure and Some Affecting Factors. Archives of Renal Diseases and Management, 3 (1): 012-019, 2017.

2- IBRAHIM S., DARWISH H. and FAYED A.: Late initiation of dialysis in diabetic Egyptian patients. The Egyptian Journal of Internal Medicine, 27 (2): 58-62, 2015.

3- TAYABAS L.T., PARTIDA-PONCE L. and HERNÁNDEZ-IBARRA L.E.: Coordinated hospital-home care for kidney patients on hemodialysis from the perspective of nursing personnel. The Revista Latino-Americana de Enfermagem, 23 (2): 105-29, 2015.

4- ALNAZLY E.K. and SAMARA N.A.: The Burdens on Caregivers of Patients above 65 Years Old Receiving Hemodialysis: A Qualitative Study. Health Care Current Reviews, 118 (2), 2014.

5- MASHAYEKHI F., PILEVARZADEH M. and RAFATI F.: The assessment of caregivers burden in hemodialysis patients. United States National Library of Health, 27 (5): 333-6, 2015.

6- JADHAV S.B., DHAVALE H.S., DERE S.S. and DADARWALA D.D.: Psychiatric morbidity, quality of life and caregiver burden in patients undergoing hemodialysis. The Medical Journal of DPU, 7 (6): 722-7, 2014.

7- KAAKINEN J., COEHLO D., DUFF V. and HANSON S.: Family Health Care Nursing Theory, Practice and Research Text Book, 4 th ed., pp. 249-51, 2010.

8- EL-ABBASSY A., ATIA M. and ALAM F.: The effectiveness of Practical Guides on Burden's Coping Strategies among Caregiver of Children Undergoing Hemodialysis. International Journal of Nursing, 2 (2): 128-43, 2015.

9- EL-MELEGY O.A., AL-ZFTAWY A.M. and KHATON S.E.: The effect of family centered empowerment model on hemodialysis patients and their caregivers. Journal of Nursing Education and Practice, 11 (6): 119-32, 2016.

10- GILL A., SINGH A., MATREJA P., GUPTA A., SINGH N. and KHOSLA P.: Assessment of the quality of life of caregiver's of patients suffering from chronic kidney disease. BANTAO Journal, 9 (2): 31-5, 2011.

11-ABD EL-MOUTY M., SAMIA ABD EL-AZIZ, HEDEYA
HABIB and S. NAGAT: Assessing the quality of life among lepromatous patients in mansoura city, 2004.

11-ALNJADAT R.M.: Predicting factors affecting the Quality of Life among Malaysian caregivers of cancer patients. Journal of Medicine and Medical Sciences, 5 (6): 294-8, 2017.

12- PINEDO S., SANMARTIN V., ZALDIBAR B., MIRANDA M., TEJADA P., ERAZO P., LIZARRAGA N., AYCART J., GAMIO A., GÓMEZ I. and BILBAO A.: Quality of Life of Stroke Patients and their Caregivers. International Journal of Physical Medicine \& Rehabilitation, 5: 387. doi: 10.4172/2329-9096.1000387, 2017.

13- VINCENT-ONABAJO G., ALI A. and HAMZAT T. Quality of life of Nigerian informal caregivers of community-dwelling stroke survivors. Scandinavian Journal of Caring Sciences, 27 (4): 977-82, 2013.

14- OPOKU-BOATENG Y.N., KRETCHY I.A., ARYEETEY G.C., DWOMOH D., DECKER S., AGYEMANG S.A., TOZAN Y., AIKINS M. and NONVIGNON J.: Economic cost and quality of life of family caregivers of schizophrenic patients attending psychiatric hospitals in Ghana. BMC Health Services Research, 17 (4), 2017.

15- AMENDOLA F., OLIVEIRA M.D. and ALVARENGA M.R.: Influence of social support on the quality of life of family caregivers while caring for people with dependence. Revista da Escola de Enfermagem da USP, 45 (4), 2011.

16- WINAHYU K., HEMCHAYAT M. and CHAROENSUK S.: Factors Affecting Quality of Life among Family Caregivers of Patients with Schizophrenia in Indonesia. Journal of Health Research, 29 (1): 77-82. Available at: www.tci-thaijo.org/index.php/jhealthres/article/view/ 79895, 2015.

17- VANZ A.P., FÉLIX T.M., Da ROCHA N.S. and SCHWARTZ I. D.: Quality of life in caregivers of children and adolescents with Osteogenesis Imperfecta. Health and Quality of Life Outcomes, 41 (13), 2015.

18- KILIC H.F. and KAPTANOGULLARI H.: A Bicommunal Study: Burden of Caregivers of Hemodialysis. Patients. International Journal of Caring Sciences, 10 (3): 138290, 2017.

19- YILDIRIM Y., KILIC S.P. and AKYOL A.D.: Relationship between life satisfaction and quality of life in Turkish nursing school students. Journal of Nursing Education and Practice, 15 (4): 415-22, 2013.

20- GARRIDO S., MÉNDEZ I. and ABELLÁN J.: Analyzing the simultaneous relationship between life Satisfaction and health-related quality of life, Journal of happiness studies, 14 (6): 1813-38, 2013. 


\section{نوعية الحياة لدى مقدمى الرعاية الآسرية للمرضى الخاضعين لغسيل الكلى الريلى}

الهدف من البحث: يهدف هذا البحث إلى "تقيم نوعية الحياة لدى مقدمى الرعاية الآسرية المرضى الخاضعين لغسيل الكلى".

تصميم البحث: :إستخدام تصميم الوصفى ليناسب الغرض من الدراسة (A descriptive design).

العينة ومكان البحث: آجريت هذه الدراسة فى قسم الغسيل الكلوى والديلزة التابع للعيادات الخارجية بمستشفى القصر العينى. مجموع العينة . آ مقدم رعاية آسرية.

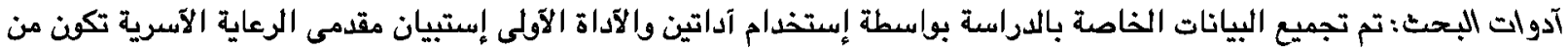

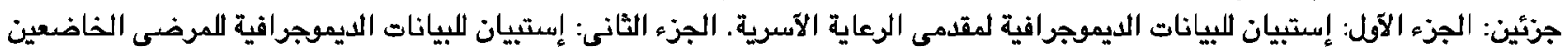

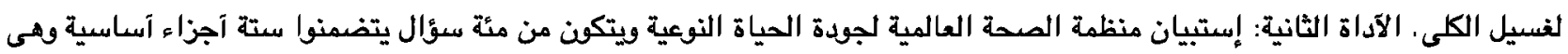

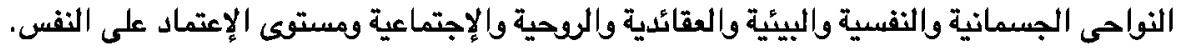

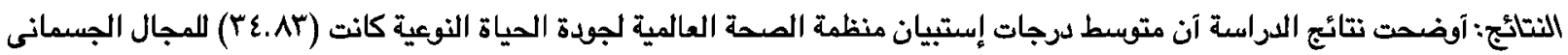

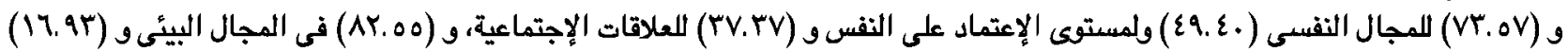

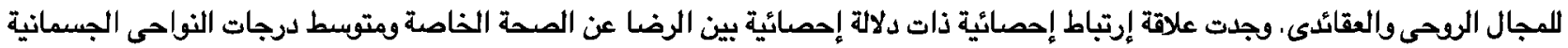

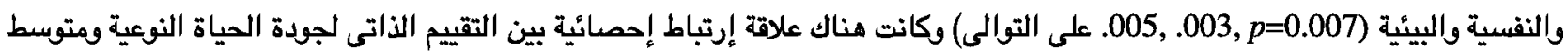

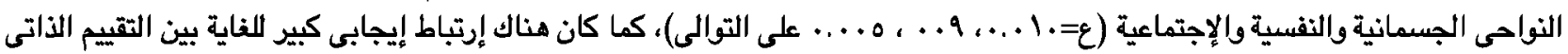

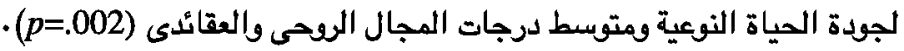

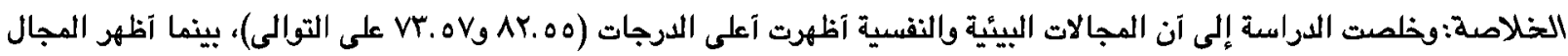

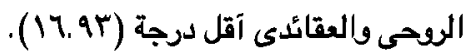

التوصيات: وإستنادا إلى نتائج الدراسة الحالية، يمكن تقديم التوصيات الآتية: • تصميم برامج تعليمية لمقدمى الرعاية الآسرية بخصوص غسيل الكلى ومضاعفاته المشتبه فيها والعناية اللازمة. • تنفيذ برنامج تعليمى لمقدمى الرعاية الآسرية بخصوص غسيل الكلى ومضاعفاته المشتبه فيها والعناية اللازمة. • تصميم وتنفيذ برامج التمكين لمقدمى الرعاية الآسرية قبل البدء فى جلسات الغسيل الدموى لإعدادهم للقيام بمهمة الرعاية الآسرية. 